\title{
ANALISIS EFISIENSI SALURAN PEMASARAN IKAN LELE DI DESA RASAU JAYA 1 KECAMATAN RASAU JAYA KABUPATEN KUBU RAYA
}

\author{
Dani Apriono'), Eva Dolorosa ${ }^{2)}$, Imelda ${ }^{2)}$ \\ 1) Mahasiswa Fakultas Pertanian Universitas Tanjungpura Pontianak \\ 2) Dosen Fakultas Pertanian Universitas Tanjungpura Pontianak
}

\begin{abstract}
This study aims to determine the level of efficiency in the marketing channel catfish every marketing agencies. The method used is a survey method. Sampling was conducted with a random sample of respondents is simple. The number of samples in this study were 32 respondents catfish farmers while the sample population was taken marketing agency comprised of three retailers, 1 traders and 2 wholesalers.

There are three marketing channels used in the Village pembudidaya Rasau Jaya Jaya District 1 District Rasau Fort Wayne to market catfish produced, ie (1) PembudidayaRetailer-Consumer, (2) Pembudidaya-Big Trader-Retailer-Consumer, (3) Pembudidayacollectors-Great Traders-Retailer-Consumer. The entire marketing channel catfish has been efficient, but when seen from the comparison of margins and the farmer's share of the marketing channel I was most marketing channels efiesien. The marketing function is generally performed by a marketing agency involved in the marketing process is a function of exchange catfish and physical function. The cultivation of catfish farmers in the village do Rasau Jaya 1 is efficient to do, is seen from the value of the comparison between the reception and the $\mathrm{R} / \mathrm{C}$ ratio of the total cost.
\end{abstract}

Keywords: Efficiency of marketing, the marketing function, profit. 


\section{PENDAHULUAN}

Salah satu komoditi perikanan yang memiliki prospek cukup baik untuk dikembangkan sebagai ikan konsumsi adalah Ikan Lele ( Clarias sp.). Konsumsi ikan lele telah menjadi suatu kebutuhan yang harus dijamin ketersediannya. Hal ini disebabkan tingginya permintaan ikan lele baik untuk kebutuhan konsumsi rumah tangga maupun kebutuhan usaha kuliner seperti lamongan.

Konsep efisiensi pemasaran pada dasarnya adalah suatu ukuran relatif. Efisiensi pemasaran adalah bentuk awal dari bekerjanya pasar persaingan sempurna, yang artinya sistem tersebut dapat memberikan "kepuasan" bagi lembaga-lembaga pemasaran yang terlibat. Efisiensi pemasaran dapat dibedakan atas efisien teksis dan efisiensi ekonomi (Sudiyono, 2004). Usaha perbaikan dibidang pemasaran memegang peranan penting karena usaha peningkatan produksi saja tidak akan meningkatkan pendapatan pembudidaya ikan lele bila tidak didukung dan dihubungkan dengan situasi pasar. Situasi demikian sangat menentukan keefisiensian suatu usaha. Pemasaran dianggap efisien apabila mampu menyampaikan hasil dari produsen ke konsumen dengan biaya semurahmurahnya dan mampu mengadakan pembagian yang adil dari keseluruhan harga yang dibayarkan konsumen akhir kepada semua pihak yang terlibat dalam produksi dan pemasaran barang tersebut. Apabila bagian yang diterima pembudidaya ikan lele menguntungkan, hal ini akan merangsang pembudidaya ikan lele lainnya untuk meningkatkan produksinya. Dalam penyampaian komoditas dari produsen ke konsumen terdapat beberapa kegiatan pemasaran yang dilakukan oleh lembaga perantara seperti pengangkutan jarak antara pembudidaya dan konsumen akan mencerminkan panjang pendeknya saluran pemasaran. Adanya biaya pada setiap lembaga pemasaran akan mengambil keuntungan atas segala jasa atau peran aktif sebagai penghubung antara produsen dan konsumen. Hal ini akan mendorong terjadinya perbedaan harga pada masing-masing lembaga pemasaran (Kotler,2002).

Pada tahun 2010 di Pasar Flamboyan Pontianak jumlah pemasokan ikan tongkol hitam paling banyak untuk jenis ikan laut bila dibandingkan dengan udang gala maupun udang merah, sedangkan untuk ikan air tawar pemasokan terbesar untuk Pasar Flamboyan yaitu ikan nila. Walaupun jumlah pemasokan ikan lele lebih rendah dibandingkan dengan pemasokan ikan nila namun perbedaan pemasokan keduanya tidak berbeda jauh. Sehingga permintaan konsumen terhadap ikan lele di Kota Pontianak cukup tinggi, ini dapat dilihat pada tabel 1. 
Tabel 1. Jumlah Pemasokan Ikan Laut/Tawar di Pasar Flamboyan Menurut Jenis Ikan Setiap Bulannya (Ton) 2010

\begin{tabular}{lcccccc}
\hline \multirow{1}{*}{ Bulan } & \multicolumn{7}{c}{ Jenis Ikan } \\
\cline { 2 - 7 } & $\begin{array}{c}\text { Tongkol } \\
\text { Hitam }\end{array}$ & $\begin{array}{c}\text { Udang } \\
\text { Gala }\end{array}$ & $\begin{array}{c}\text { Udang } \\
\text { Merah }\end{array}$ & Lele & Nila & Jumlah \\
\hline Januari & 35,50 & 0,60 & 25,60 & 9,76 & 11,60 & 83,06 \\
Februari & 36,20 & 1,10 & 29,10 & 10,45 & 11,95 & 88,80 \\
Maret & 37,50 & 2,00 & 27,10 & 11,90 & 13,10 & 91,60 \\
April & 53,50 & 7,50 & 24,00 & 11,00 & 10,00 & 106,00 \\
Mei & 36,00 & 1,00 & 30,50 & 7,50 & 19,50 & 94,50 \\
Juni & 42,50 & 10,00 & 26,00 & 13,00 & 13,00 & 104,50 \\
Juli & 53,50 & 8,50 & 27,10 & 11,00 & 10,00 & 110,10 \\
Agustus & 58,00 & 8,50 & 27,10 & 12,00 & 11,00 & 116,60 \\
September & 68,00 & 7,00 & 18,00 & 13,00 & 10,00 & 116,00 \\
Oktober & 70,50 & 4,00 & 19,00 & 14,00 & 11,50 & 119,00 \\
November & 58,00 & 2,00 & 11,50 & 13,00 & 11,50 & 96,00 \\
Desember & 54,60 & 1,50 & 1,50 & 12,00 & 12,00 & 81,60 \\
\hline Kota Pontianak & 603,80 & 53,70 & 266,50 & 138,61 & 145,15 & 1207,76 \\
\hline Rata-Rata/Bulan & 50,32 & 4,48 & 22,21 & 11,55 & 12,10 & 100,65 \\
\hline Sumber: Dinas Pertanian Perikanan dan Kehutanan Kota Pontianak, 2011
\end{tabular}

Margin pemasaran merupakan konsep penting dalam kajian efisiensi yang kemudian dapat menentukan apakah pemasaran efisien atau tidak. Margin pemasaran terdiri dari dua bagian yaitu, bagian pertama merupakan perbedaan antara harga yang dibayar konsumen dengan harga yang diterima oleh produsen dalam hal ini pembudidaya ikan lele. Bagian yang kedua margin pemasaran merupakan biaya dari jasa-jasa pemasaran yang dibutuhkan sebagai akibat permintaan, penawaran dan jasa-jasa pemasaran tersebut. Komponen margin pemasaran ini terdiri dari : (1) biaya-biaya yang diperlukan lembaga-lembaga pemasaran untuk melakukan fungsi-fungsi pemasaran yang disebut biaya pemasaran atau biaya fungsional (functional cost) dan (2) keuntungan (profit) lembaga pemasaran (Sudiyono,2004).

\section{METODE PENELITIAN}

Metode yang digunakan dalam penelitian ini adalah metode survey yaitu penelitian dilakukan dengan cara mengambil sampel dari satu populasi dan menggunakan kuesioner sebagai alat pengumpulan data yang pokok, serta mendatangi langsung lokasi penelitian untuk memperoleh informasi yang diperlukan dalam penelitian (Nazir, 2005).

Lokasi penelitian dipilih secara sengaja (purposive) yaitu di Desa Rasau Jaya 1 Kecamatan Rasau Jaya Kabupaten Kubu Raya dengan dasar pertimbangan banyaknya kelompok pembudidaya aktif yang membudidayakan ikan lele sebagai sumber panghasilan dan juga di daerah tersebut pembudidaya kebanyakkan menghasilkan bibit ikan lele sendiri yang akan dibesarkan.

Menurut Soeparmoko (1991) jika populasi N besar maka ukuran sampel minimal 30 sampel dari jumlah petani tersebut . Populasi pembudidaya ikan lele di Desa Rasau Jaya 1 Kecamatan Rasau Jaya yaitu 65 orang pembudidaya ikan lele yang tergabung ke dalam tujuh kelompok pembudidaya. Sampel pembudidaya yang diambil sebanyak 32 orang pembudidaya ikan lele dari total pembudidaya di Desa Rasau Jaya 1 yang dipilih secara proporsional dari tujuh kelompok pembudidaya yang melakukan pemasaran ikan 
lele melalui saluran pemasaran yang ada di Desa Rasau Jaya 1. Pengambilan sampel menggunakan teknik simple random sampling (sampel acak sederhana). Untuk sampel lembaga pemasaran yang terlibat diambil keseluruhan populasi yang ada yaitu 3 pedagang pengecer, 2 pedagang besar dan 1 pedagang pengumpul.

\section{ANALISIS DATA}

1. Analisis Efisiensi Pemasaran

Analisis efisiensi pemasaran ini dilakukan untukk mengetahui efisiensi pemasaran ikan lele. Indikator-indikator yang digunakan sebagai berikut:

a. Menurut Hanafiah dan Saefuddin (1982), Marjin pemasaran ikan lele adalah harga yang dibayar oleh konsumen akhir dengan harga yang diterima pembudidaya (produsen) dalam rupiah per kilo gram $(\mathrm{Rp} / \mathrm{Kg})$.

$$
\text { Mi = Psi - Pbi }
$$

Keterangan :

$\mathrm{Mi}=$ Marjin pemasaran di tingkat ke-i

Psi = Harga jual di tingkat ke-i

$\mathrm{Pbi}=$ Harga jual di tingkat ke-i

\section{b. Farmer's Share}

Untuk mengetahui bagian yang diterima petani (pembudidaya) dari harga ditingkat pengecer, rumus yang digunakan adalah sebagai berikut:

$$
\frac{\text { toor, ruin }}{\text { Fs }-\frac{\cdots}{H o} \times 100 \%}
$$

Keterangan:

Fs : Farmer's Share (bagian yang diterima Pembudidaya)

$\mathrm{Hj}$ : Harga Jual Ditingkat Pembudidaya

Ho : Harga Ditingkat Pedagang Pengecer

c. Profitability Indeks (Indeks Keuntungan)

Untuk mengetahui besarnya nilai keuntungan dari biaya yang dikeluarkan oleh semua lembaga pemasaran ikan lele yang terlibat.

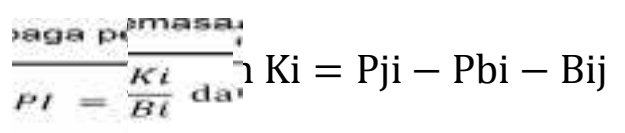

Keterangan:

$\mathrm{Ki}=$ Keuntungan pemasaran $(\mathrm{i}=1,2, \ldots \mathrm{m} ; \mathrm{m}=$ Jumlah lembaga pemasaran yang terlibat)

$\mathrm{Bi}=$ biaya pemasaran $(\mathrm{i}=1,2, \ldots \mathrm{n} ; \mathrm{n}=$ Jumlah jenis biaya $)$ 


$$
\begin{aligned}
& \mathrm{Pji}=\text { Harga jual } \mathrm{ke}-\mathrm{i} \\
& \mathrm{Bij}=\text { Biaya pemasaran lembaga } k e-\mathrm{i} \text { dari berbagai jenis }
\end{aligned}
$$

\section{Fungsi Lembaga Pemasaran}

Analisis kualitatif digunakan untuk menjawab tujuan 2 tentang fungsi setiap lembaga pemasaran ikan lele yang terlibat. Analisis kualitatif adalah analisis yang bersifat deskriptif dan cenderung menggunakan pendekatan induktif.

\section{Analisis Keuntungan Usaha Budidaya Ikan lele}

Keuntungan adalah selisih antara total penerimaan dan total biaya yang digunakan (Soekartawi, 1998). Return and Cost Ratio (R/C rasio) merupakan perbandingan antara nilai output dan inputnya atau perbandingan antara penerimaan usahatani dengan pengeluaran usahatani.

\section{$\mathrm{R} / \mathrm{C}$ rasio atas biaya total $=\mathrm{TR} / \mathrm{TC}$}

Jika nilai $R / C$ rasio lebih besar dari satu $(R / C$ rasio $>1)$, maka menunjukkan usaha tersebut mempunyai penerimaan usaha yang semakin besar sehingga kegiatan usaha tersebut efisien. Sedangkan jika nilai $R / C$ rasio kurang dari satu $(R / C$ rasio $<1)$, menunjukkan kegiatan usaha yang dilaksanakan tidak efisien karena penerimaan tidak lebih besar dari pengeluaran yang harus dikeluarkan.

\section{HASIL DAN PEMBAHASAN}

Saluran pemasaran menggambarkan proses penyaluran ikan lele dari pembudidaya sebagai produsen sampai ke tangan konsumen. Lembaga pemasaran yang terlibat didalam kegiatan pemasaran ikan lele adalah pedagang pengecer, pedagang besar dan pedagang pengumpul. Saluran pemasaran ikan lele produksi Desa Rasau Jaya 1 Kecamatan Rasau Jaya Kabupaten Kubu Raya mempunyai 3 saluran pemasaran, seperti terlihat pada gambar dibawah ini:

a. Saluran Pemasaran I

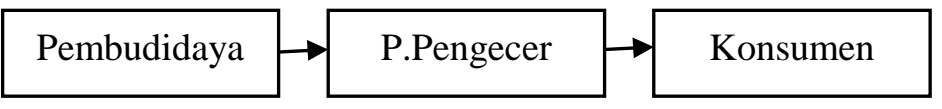

b. Saluran Pemasaran II

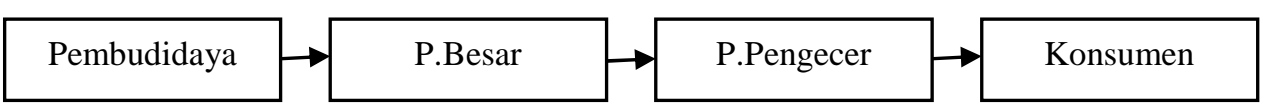

c. Saluran Pemasaran III

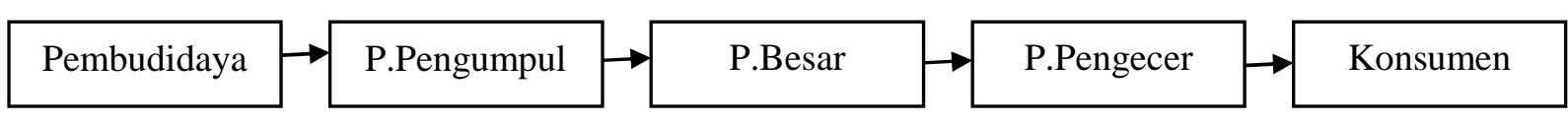

\section{Analisis Farmer's share}

Farmer's share berhubungan terbalik dengan marjin pemasaran, artinya semakin tinggi marjin pemasaran maka akan semakin rendah farmer's sharenya. Besarnya bagian yang diterima pembudidaya ikan lele dapat dilihat pada tabel 2. 
Tabel 2. Sebaran Farmer's Share Ikan Lele Per Kg Pada Setiap Saluran

\begin{tabular}{cc}
\hline Saluran Pemasaran & Farmer's Share \\
\hline Saluran I & 83,33 \\
Saluran II & 75,00 \\
Saluran III & 66,67
\end{tabular}

Sumber : Analisis Data Primer, 2012

Berdasarkan analisis data primer menunujukan saluran pemasaran yang memiliki Farmer's share tertinggi terdapat pada saluran pemasaran I yaitu sebesar $83,33 \%$, artinya pembudidaya ikan lele menerima harga sebesar $83,33 \%$ dari harga yang dibayarkan konsumen. Harga yang dibayarkan konsumen akhir sebesar Rp.24.000/Kg ikan lele, sehingga pembudidaya pada saluran pemasaran 1 memperoleh Rp.20.000 dari harga yang dibayarkan konsumen untuk $1 \mathrm{Kg}$ ikan lele.

Tabel 3. Analisis Perbandingan Farmer's Share dan Marjin Pemasaran Ikan Lele

\begin{tabular}{cccc}
\hline $\begin{array}{c}\text { Saluran } \\
\text { Pemasaran }\end{array}$ & $\begin{array}{c}\text { Farmer's Share } \\
\text { (\%) }\end{array}$ & $\begin{array}{c}\text { Marjin } \\
(\%)\end{array}$ & Keterangan \\
\hline Saluran I & 83,33 & 16,67 & FS > MP \\
Saluran II & 75,00 & 29,17 & FS > MP \\
Saluran III & 66,67 & 41,67 & FS > MP \\
\hline
\end{tabular}

Sumber : Analisis Data Primer, 2012

Berdasarkan tabel 3, bila dilihat dari nilai total marjin pemasaran dan farmer's share maka seluruh saluran pemasaran ikan lele yang ada Di Desa Rasau Jaya 1 sudah efisien, namun saluran pemasaran I merupakan saluran pemasaran yang paling efisien. Saluran pemasaran III merupakan saluran pemasaran yang paling tidak efisien ini ditunjukan dari besarnya nilai marjin pemasaran. Namun saluran pemasaran III ini yang menjadi pilihan utama pembudidaya.

\section{Analisis Profitability Indeks}

Profitability Indeks merupakan besarnya keuntungan dibandingkan dengan biaya dari lembaga pemasaran ikan lele yang terlibat. Besarnya nilai Profitability Indeks dapat dilihat pada tabel 4.

Tabel 4. Profitability Indeks Pemasaran Ikan Lele

\begin{tabular}{cccccc}
\hline \multirow{2}{*}{$\begin{array}{c}\text { Saluran } \\
\text { Pemasaran }\end{array}$} & \multicolumn{2}{c}{$\begin{array}{c}\text { Keuntungan } \\
\text { Pemasaran }\end{array}$} & \multicolumn{2}{c}{$\begin{array}{c}\text { Biaya } \\
\text { Pemasaran }\end{array}$} & \multirow{2}{*}{$\begin{array}{c}\text { Profitability } \\
\text { Indeks }\end{array}$} \\
\cline { 2 - 5 } & $\mathbf{( R p / K g )}$ & $\mathbf{( \% )}$ & $\mathbf{( R p / K g )}$ & $\mathbf{( \% )}$ & \\
\hline Saluran I & $2.747,83$ & 11.45 & 1.252 & 5,22 & 2,24 \\
Saluran II & $2.235,38$ & 9,31 & 4.765 & 19,85 & 0,47 \\
Saluran III & $2.291,31$ & 9,55 & 7.709 & 32,12 & 0,37 \\
\hline
\end{tabular}

Sumber : Analisis Data Primer, 2012

Pada tabel 4 menunjukan bahwa saluran pemasaran I memiliki keuntungan pemasaran terbesar dalam pemasaran ikan lele karena memiliki nilai profitability indeks tertinggi. Nilai profitability indeks pada saluran I sebesar 2,24 artinya jika biaya 
pemasaran sebesar Rp.100,00 maka akan memperoleh keuntungan pemasaran sebesar Rp.224,00.

\section{Fungsi Pemasaran}

Tidak semua lembaga pemasaran melakukan semua fungsi pemasaran tersebut. Fungsi yang umumnya dilakukan oleh lembaga pemasaran adalah fungsi pertukaran dan fungsi fisik. Hal ini dapat dilihat pada tabel 5.

Tabel 5. Fungsi Pemasaran Yang Dilakukan Lembaga Pemasaran Ikan Lele di Desa Rasau Jaya 1

\begin{tabular}{|c|c|c|c|}
\hline No & Lembaga Pemasaran & $\begin{array}{c}\text { Fungsi } \\
\text { Pemasaran }\end{array}$ & Kegiatan \\
\hline 1 & Pembudidaya & Pertukaran & Penjualan, Pembelian \\
\hline 2 & Pedagang Pengecer & $\begin{array}{l}\text { Pertukaran } \\
\text { Fisik } \\
\text { Fasilitas }\end{array}$ & $\begin{array}{c}\text { Penjualan, Pembelian } \\
\text { Pengemasan, } \\
\text { Pengankutan } \\
\text { Penyortiran }\end{array}$ \\
\hline 3 & Pedagang Besar & $\begin{array}{l}\text { Pertukaran } \\
\text { Fisik }\end{array}$ & $\begin{array}{c}\text { Penjualan, Pembelian } \\
\text { Pengemasan, } \\
\text { Pengankutan }\end{array}$ \\
\hline 4 & Pedagang Pengumpul & $\begin{array}{l}\text { Pertukaran } \\
\text { Fisik } \\
\text { Fasilitas }\end{array}$ & $\begin{array}{c}\text { Penjualan, Pembelian } \\
\text { Pengemasan, } \\
\text { Pengankutan } \\
\text { Penyortiran }\end{array}$ \\
\hline
\end{tabular}

Sumber:Data Primer,2012

Tidak setiap lembaga pemasaran melakukan semua fungsi pemasaran karena ada saatnya suatu fungsi pemasaran dilakukan oleh satu atau beberapa lembaga pemasaran tetapi tidak dilakukan oleh lembaga lainnya. Namun ada fungsi pemasaran yang dilakukan oleh setiap lembaga pemasaran seperti fungsi pertukaran, yaitu fungsi pembelian dan penjualan.

Revenue and Cost Ratio (R/C rasio) merupakan perbandingan antara nilai output dan inputnya atau perbandingan antara penerimaan usahatani dengan pengeluaran usahatani. Dalam penelitian ini merupakan perbandingan penerimaan dengan pengeluaran pembudidaya untuk usaha budidaya ikan lele.

Tabel 6. (R/C Rasio) Usaha Budidaya Ikan Lele

\begin{tabular}{cc}
\hline Uraian & Nilai R/C Rasio \\
\hline Saluran Pemasaran I & 1,48 \\
Saluran Pemasaran II & 1,38 \\
Saluran Pemasaran III & 1,37 \\
\hline
\end{tabular}

Sumber : Analisis Data Primer, 2012

Pada tabel 6 menunjukan bahwa nilai perbandingan antara penerimaan dan $(R / C$ rasio) atas biaya total, saluran pemasaran I merupakan nilai tertinggi dibandingkan saluran pemasaran II dan saluran pemasaran III untuk satu siklus produksi per musim. 


\section{KESIMPULAN}

Berdasarkan uraian hasil penelitian maupun pembahasan, maka dapat diperoleh kseimpulan sebagai berikut:

1. Seluruh saluran pemasaran ikan lele di Desa Rasau Jaya 1 sudah efisien, tetapi bila dilihat dari perbandingan nilai marjin dan farmer's share maka Saluran pemasaran I merupakan saluran pemasaran yang paling efiesien yang melibatkan pembudidaya pedagang pengecer - konsumen. Ini ditinjau dari marjin pemasaran, farmer's share, dan profitability indeks.

2. Ditinjau dari lembaga pemasaran yang terlibat, keuntungan terbesar didapat oleh pembudidaya yang menggunakan saluran pemasaran I sedangkan keuntungan terkecil diperoleh pembudidaya yang menggunakan saluran pemasaran III. Untuk pedagang perantara, keuntungan terbesar didapat oleh pedagang pengecer saluran pemasaran I.

3. Lembaga-lembaga pemasaran yang terlibat dalam pemasaran ikan lele ini melakukan fungsi-fungsi pemasaran yang terdiri dari fungsi pertukaran, fungsi fisik dan fungsi fasilitas. Namun tidak semua fungsi pemasaran tersebut dilakukan oleh semua lembaga pemasaran.

4. Analisis pendapatan usaha budidaya ikan lele diperoleh nilai $\mathrm{R} / \mathrm{C}$ rasio tertinggi untuk saluran pemasaran I. Namun baik saluran pemasaran I, II maupun III tergolong efisien untuk dilaksanakan.

\section{DAFTAR PUSTAKA}

Dinas Pertanian, Perikanan dan Kehutanan Kota Pontianak. 2011. Statistik 2011. Kota Pontianak

[DKP] Departemen Kelautan dan Perikanan. 2011. Analisis Data Statistik 2007. Kalimantan Barat

Hanafiah, A.M, dan Saefuddin A.m. 1986. Tataniaga Hasil pertanian. UI Press. Jakarta

Kotler, Philip. 2002. Menejemen Pemasaran, Analisis, Perencanaan, implemntasi, dan Kontrol. Jilid I. PT.Prenhalindo. Jakarta

Nazir, M. 2005. Metode Penelitian Sosek. Galia Indonesia. Jakarta

Soekartawi. 1988. Prinsip Dasar Ekonomi Pertanian. Universitas Indonesia Press. Jakarta.

Soeparmoko.1991. Metode Penelitian Praktis. Edisi Ketiga BPFE. Yogjakarta.

Sudiyono, Armand. 2004. Pemasaran Pertanian. Umm Press. Malang 